\title{
Advantages of modern collapsible systems for exterior finishing of buildings in urban areas in Russia
}

\author{
Kristina Tolstova ${ }^{1,}{ }^{*}$, Vitaly Chulkov ${ }^{1, * *}$ \\ ${ }^{1}$ Moscow State University Of Civil Engineering 129337, 26, Yaroslavskoe shosse, Moscow, Russian Federation
}

\begin{abstract}
Traditionally, the method of finishing interior spaces, as well as exterior surfaces and architectural and structural elements of buildings and structures is widely used, when layers of building materials or finishing structures are applied in a strict sequence, allowing them to eventually form an unbroken whole - a "monolith". This method of finishing, its technology and results not only depend significantly on the quality of the materials used and the mechanization of processes, but also require high qualification and specialization of construction workers. The execution of such a finish is more an art than a reproduced with a given level of quality of results by a technological process. An alternative to "monolith" is a variety of collapsible (they are also called "hinged") systems for finishing urban buildings, the elements of which are manufactured in the construction industry, requiring, as a rule, only installation and assembly in internal premises (the so-called "evroremont"), Or on the external surfaces of a building or structure.
\end{abstract}

\section{Introduction}

Means of protection for worn out and lost to a certain extent their physical and aesthetic characteristics of the surfaces of premises and facades of building objects, people used for centuries. In the overwhelming majority, these were different versions of the known method, when solutions and paints were applied to the prepared substrate, allowing the previous layer to dry before applying the subsequent layer. Approximately from the 70 s of the last century, materials and technologies of construction and installation works abroad allowed to use another method of finishing the surface of buildings - "hinged systems". The need for preliminary preparation of the base ("continental surface") has disappeared, since it is "hung" the metal frame to be mounted, to which then the facing products are fastened. The number of varieties of the results of this method of finishing is very great.

Publications of foreign authors (Carlsson, P., 2003, [1], 2005, [2], Deneyer, A., Moenssens, N., 2004, [3]; Lang W., Cremers J., Beck A., Manara J. et al., 2013, [4, 5] Hamidi S., Ewing R., 2014, [6] Hennig E., Schwick C., Soukup T., Orlitova E., Kienast F., Jaeger J ., 2015, [7], Zeković S., Maričić T., Vujošević M., 2016, [8] and a number of them preceded) are devoted to the promotion of certain types of hanging facades and used finishing materials (metal, plastic, glass and others) ).

Recently publications of domestic authors appeared in foreign professional publications (for example, Vatin N., Nemova D., Kazimirova A., Gureev K., 2014, [9], Aristov D., Glotova Yu., Sazonova Yu., Tyulenev M., 2015, [11] and a number of others), as well as dissertation research (for example, - Olshevsky V., 2014, [10]), who also consider local cases of using variants of hinged facades and finishing materials.

System studies of the class of collapsible hinged systems in Russia began in 2006 Kuzina O.N. She called the process of forming such systems "retreat" (from English Retrieve - to restore, find, attach) [12].

This article is devoted to continuing research on this topic. In Russia, in the conditions of a market economy, different kinds of market construction products, related to the class of collapsible hinged interior finishing systems and external surfaces of buildings and structures for different special purposes, have emerged and are competing with each other. Such a variety of names and manufacturers of components for different finishing systems is

\footnotetext{
${ }^{*}$ Corresponding author: kristi.tolstova@gmail.com

*** Corresponding author: vitolch@gmail.com
} 
encouraging in the competitive market in the construction products market. But, from the scientific point of view, all this diversity refers to one class of retrieval systems, methods and processes of their application in construction.

\section{Methods}

The basis of scientific study of the class of retracement systems, methods and processes of their application in construction is the basic infographic model of the reorganization cycle, which consists of four stages (Fig. 1):

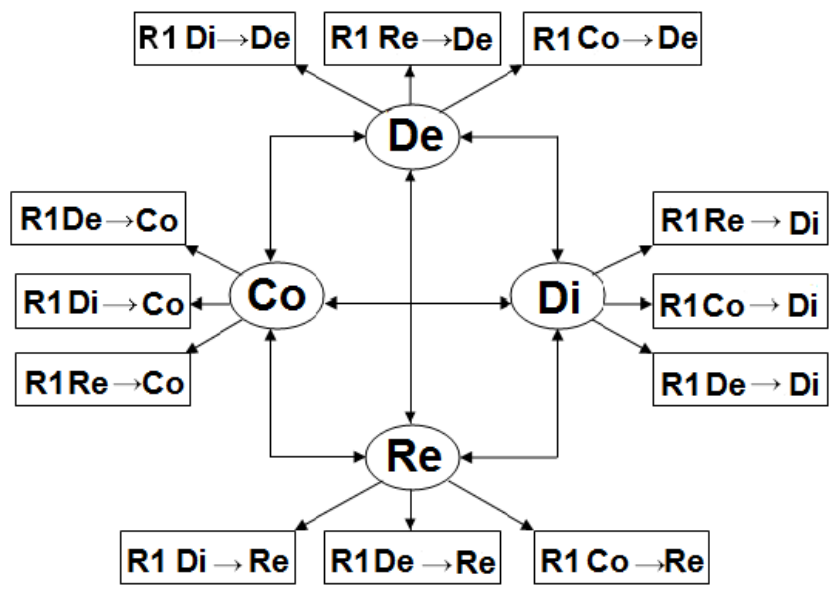

Fig.1. Interaction of the stages of the basic reorganization cycle in the construction

of $\mathrm{De}, \boldsymbol{D i}, \boldsymbol{R e}$ and $\mathrm{Co}$ and its results $\mathrm{RI}$

- The device, $\boldsymbol{D e}$, as a certain state of stability with predefined (projected and implemented) characteristics and parameters that meet the requirements of a certain position in the activities of society; In the construction industry, this may be a building or a structure erected anew on the basis of previously designed structural and organizational and technological projects;

- Disorganization, Di, as formed by a well-known array of personalities from a certain point of view and with known goals, an idea of the building or structure erected at the stage of "device", as inconsistent with the point of view and goals of the disorganization figures; It is assumed that these claims of disorganizers are set out in substantive texts reflected in documents available for review;

- Reorganization, $\boldsymbol{R e}$, as the process of reconstruction of a building or structure in accordance with proposals of disorganizers, discussed with specialists of the construction industry and interested public of the society; The results of such a discussion should form the basis for the developed constructive and organizational and technological projects for such reconstruction of these buildings or structures;

- Co-organization, Co, as the process of correct (approved, perceived positively) perception of necessity and realization of the construction reorganization formed by the disorganizers and developers of constructive and organizational-technological projects for the reconstruction of these buildings or structures; If the co-organization is executed qualitatively, then the reconstructed building or structure takes its place at the stage of "device" of the basic reorganization cycle.

The processes of retracement are realized at the interconnected stages $\boldsymbol{D e}$ and $\boldsymbol{R} \boldsymbol{e}$ of the basic reorganization cycle (Fig. 1), in which the industrial labor activity is directly realized. At the interrelated stages, $\boldsymbol{D} \boldsymbol{i}$ and $\boldsymbol{C o}$ carry out a cogitative activity in the modeling and implementation of stages $\boldsymbol{D e}$ and $\boldsymbol{R} \boldsymbol{e}$. 


\section{Results}

The compounds obtained in non-collapsible and collapsible methods are referred to as "composites" - inhomogeneous continuous entities in which two types of components are functionally distinguished (Fig. 2):
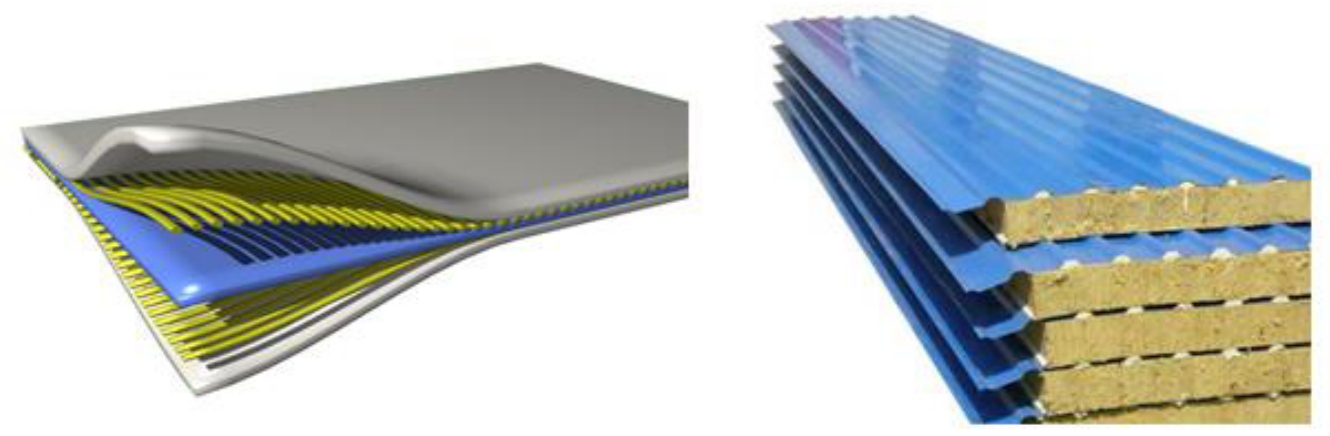

Fig.2. Examples of the structure of the functional components of the "composite"

- reinforcing (provide the necessary mechanical characteristics of the composite);

- binders or "matrix" (ensure the joint work of reinforcing components).

The increase in the static strength of the separately considered components of the composite does not lead to a decrease, but to an increase in the fracture toughness characteristics of the composite as a whole.

Two states are distinguished in the formation and monitoring of composites:

- statics - fixed at a certain moment of time by the instrument-technical or model-analytical diagnostics, the unchanged state and the aggregate values of the parameters of the composite, their compliance with the norm at the time of diagnosis;

- dynamics - a sequence of static states of the composite in time and space, fixed by statistical computer monitoring to reveal the evolution of the performance of the composite.

Modern building collapsible systems are used both for interior planning and decoration (improving the comfort of living in the process of its vital activity or labor productive activity) and for protecting (prolonging the "life") of external enclosing surfaces and structures (the facade of a building or structure) from the harmful effects of the building environment, giving the facade an attractive appearance.

Collapsible finishing systems ensure the implementation of one of the new modern varieties of building reconstruction - retrevatsia.

The study of regularities, properties and terminology in the field of retrieval is just beginning and, as is often the case, the practice of business processes of building reconstruction outstrips scientific research. Each business sector in the construction or a group of companies of a similar orientation uses or suggests the most appropriate combination for the advancement of its version of the collapsible system for the finishing of buildings and structures and the technology that implements it (that is, the business product and business services):

Facade systems;

Translucent finishing systems;

Planar glazing;

Glass facades; 
Hinged facing systems;

Ventilated facades;

Wet facades; Hinged facades; Systems of "evroremont”, etc.

The listed and many other business conjuncture names represent special cases of implementation of hinged retrieval finishing systems - composite structures from different products and materials, depending on the purpose of the erected or rearranged building, its design, the chosen architectural solution and the customer's wishes.

\section{Discussion}

The most common representative of the retracement systems for exterior decoration of buildings is a hinged ventilated facade (HVF) - a cladding composite (protective decorative shield of plates or sheet protective and decorative materials) and a structure that is fixed to the wall so that between the protective and decorative coating and the wall there is air gap. External insulation of enclosing structures can improve the indoor climate.

Due to the pressure difference, the air gap acts as a "exhaust pipe" for the upward flow, with which excess heat, atmospheric and internal moisture leave the building's enclosing structure. A ventilated air gap is "a temperature buffer that reduces heat loss (air in it is about $3{ }^{\circ} \mathrm{C}$ higher than outside). The wall of the building remains warm and dry, and in the summer the HVF works like a sun shield (it reflects a part of the heat flux incident on it).

Specially developed design and technology of installation of illegal armed units to the building provide the absorption of deformation from diurnal and seasonal temperature differences, reduction of internal stresses in the protective decorative screen and skeleton, reduction of the probability of cracking and destruction of illegal armed formations.

Among the advantages of HVF include:

- soundproofing;

- thermal insulation;

- heat insulation;

- protection against precipitation;

- compensation of thermal deformations;

- natural ventilation of water vapor;

- fire safety.

Let's consider in more detail each of the listed advantages of illegal armed formations of HVF.

Soundproofing. Joint application of the hinged facade and soundproof materials and products provides the required level of sound absorption over a wide frequency range.

Thermal insulation. The excessive accumulation of heat inside the building is hampered by the joint application of a special profile system for hinged facades and a heat insulator providing natural ventilation of the facade. The comfort of the microclimate in the room is achieved without the use of additional expensive air conditioning systems, which, in addition to the positive effect, can harm human health in the emergency mode of their application.

Heat insulation. The effects of precipitation and the occurrence of condensation significantly reduce the heat-saving properties of the insulation. The presence of a heater, protected from the effects of precipitation and condensation and the profile system of the ventilated facade, allows reducing energy consumption for heating, reducing the thickness of the bearing walls, thereby reducing the load on the foundation of the building or structure.

Protection against precipitation. The design of the main bearing profile of the HVF is designed in such a way that all the moisture that gets to the surface of the facade is removed into the drainage and has no direct contact with the heater and the building wall. 
Compensation for thermal deformations. The specially designed scheme of mounting and fixing to the wall of the NVF profile system provides the possibility of absorbing the temperatures of the so-called "thermal deformations" arising during the diurnal or seasonal changes. Thermal deformations cause internal stresses in the materials of the bearing structure of an HVF and in facing materials, which are compensated for by the movable or rigid fixation of the elements of the HVF fastening system. In this case it is necessary:

- ensure freedom of thermal deformation of HVF panels to avoid their destruction;

- to withstand the size and location of the rusts, so that disturbances in the geometry and location of the rust do not reduce the architectural expressiveness of the facade.

Natural ventilation of water vapor. The water vapor arising in the walls of buildings and structures during their operation is removed due to natural ventilation provided for in the HVF system. Such ventilation significantly improves the thermal insulation properties of the building walls, while ensuring a comfortable temperature regime in the interior. The air layer in the HVF distinguishes it from other types of facades. Differential pressure transforms this air "jumper" into a kind of "exhaust pipe", through which internal and atmospheric moisture is removed. This ventilation duct also reduces heat loss, and the air temperature inside the facade is several degrees higher than outside.

Fire safety. Hinged facades include materials and products that are classified as difficult to burn or not combustible (that is, preventing the spread of fire). The gap between the surface of the building and the decorative screen in the HVF constantly moves the air. This air flow with the use of materials with a high degree of flammability can spread fire throughout the building in a few minutes. The main material that is recommended in such cases for thermal insulation is stone wool, which is not combustible, so it has no restrictions on the number of storeys of buildings and is an excellent material that makes the facades an order of magnitude safer. High resistance to high temperatures, exceeding several hundred degrees, makes stone wool an excellent thermal insulation material.

Refusal from "wet" (for example - glutinous) technologies, their replacement by mechanical connections allows to install and reconstruct HVF at any time of the year. The absence of special requirements to the surface of the bearing wall of the building and the mobility of the junction points in order to compensate for dynamic loads (wind, temperature changes, etc.) ensure the simplicity and high speed of installation of all components of the HVF, their long overhaul life (from 25 to 50 years depending from the materials used), Fig.3.

In the Russian market there are many different domestic and foreign illegal armed groups:

Producer Russia: Alcon Trade (U-kon), Diat, Kaptechnostroy and MOSMEK, Plant Metalware (CTS), Technocom, ARKADA and others;

Manufacturer Austria: SLAVONIA (SPIDI), EUROFOX (in Russia it is represented by Duvils and Mirage companies);

Manufacturer Germany: BWM, WAGNER-SISTEM (represented by TECHNOCOM); Manufacturer Holland: HUNTER DUGLAS and many others.

Each of the listed systems HVF has a number of design features that ensure its optimality in solving specific problems (for example, when: smoothing the unevenness of the bearing wall of the building, reducing the negative effect of the "cold bridges", ensuring the possibility of fastening the small-sized cladding without significantly increasing the guide frame; Heat-insulating plates, etc.). 


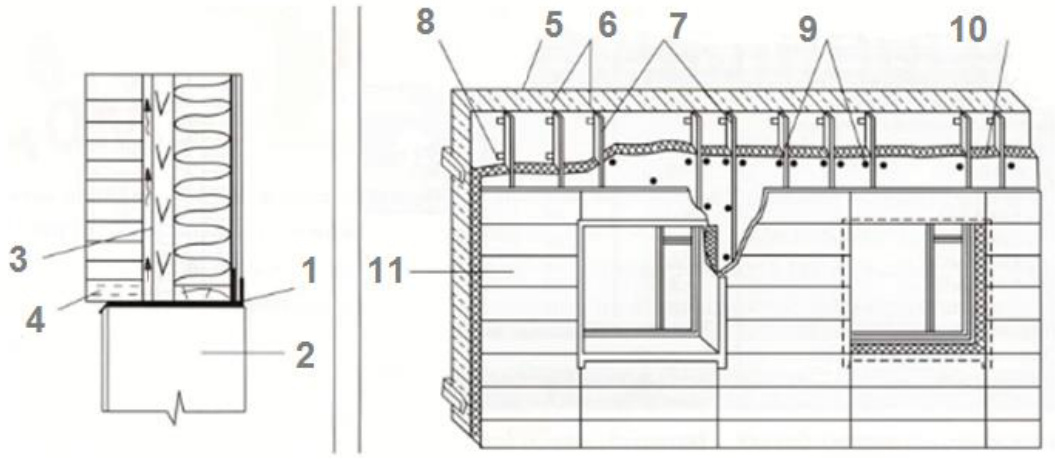

1 - waterproofing (membrane, roofing material, hydroglass, bokroelast); 2 - socle; 3 - ventilated gap; 4 - ventilated air; 5 - insulated wall; 6 - nodes of fastening of guides; 7 - metal guides; 8 - insulation, covered with windproof material; 9 - dowels; 10 - air layer; 11 - outer lining.

Fig.3. Structure diagrams (left) and installation (right) HVF

The practice of using foreign HVF in Russian conditions allowed to work out ways of adapting these hinged systems:

- reduction of the contact area of the metal with the wall ("point contact");

- use of different heat-insulating pads (foreign companies use different plastics, domestic companies often use an effective heat-insulating device "paronite").

\section{Conclusions}

The introduction of HVF in Russia is accompanied by a number of problems not known to foreign manufacturers of these systems (significant wall irregularities, very significant differences in winter and summer temperatures, etc.). They force the builders of any foreign HVF system, even a very high level, to adapt to Russian conditions (in particular - solving the important problem of the possible formation of "cold bridges".

There are two approaches to solving this problem:

- reduction of the contact area of the metal with the wall ("point contact");

- use of different insulating gaskets (foreign companies use different plastics as such gaskets, Russian campaigns often use an effective heat-insulator "paronite").

Both approaches have advantages and disadvantages.

With point fixing, the thermal conductivity is lower, but at the same time the load-carrying capacity of the brackets to the wall decreases.

With increasing contact area, the problem of forming "cold bridges" becomes more complicated.

Alternative HVF - a wet facade, it is erected, as a rule, with the use of thin-layer plaster for repair and decoration works on historical sites, where it is important to preserve the architectural appearance of the building. The facade is decorated in a warm, dry season.

In European countries, "wet" facades are erected by attaching thermal insulation material to the wall surface with glue or mechanical fasteners, and then plaster, fiberglass and synthetic materials are applied.

Such technology provides an individual textured solution of facades, warmth of slopes, less laboriousness of work execution and the possibility of further renovation of the facade during repair or reconstruction.

While in the systems of "wet" facades import components prevail and it is difficult to single out an undoubted leader in the production of high-quality domestic materials and components for the "wet" facade technology. 


\section{References}

1. Carlsson, P., 2003. Glazed facades - double skin facades: requirements and methods. Arkus (The forum of research and development of the architects), Stockholm, Sweden (in Swedish).

2. Carlsson, P., 2005. Construction with glass. Swedish glass trade union, Stockholm, Sweden (in Swedish).

3. Deneyer, A., Moenssens, N., 2004. Ventilated double skin facades - Aspects regarding natural lighting and visual comfort. Belgian Building Research Institute, Dept. of Building Physics, Indoor Climate and Building Services.

4. New Envelopes for old Buildings - the Potential of using Membrane Systems for the thermal Retrofitting of existing Buildings. / Lang W., Cremers J., Beck A., Manara J. // Life-Cycle and Sustainability of Civil Infrastructure Systems Proceedings of the Third International Symposium on Life-Cycle Civil Engineering (IALCCE'12), Vienna, Austria, October 3-6, 2012 / Edited by A. Strauss, D. Frangopol, K. Bergmeister.- London, 2013.- P. 1737-1744

5. The system of external insulation of building facades. Encyclopedia of safety. Surviving in the city (http://survincity.com/2013/12. Decamber 6th, 2013)

6. S. Hamidi, R. Ewing, A longitudinal study of changes in urban sprawl between 2000 and 2010 in the United States, Landscape and Urban Planning, 128, pp. 72-82 (2014)

7. E. Hennig, C. Schwick, T. Soukup, E. Orlitova, F. Kienast, J. Jaeger, Multi-scale analysis of urban sprawl in Europe: Towards a European desprawling strategy, Land Use Policy, 49, pp. 483-498 (2015)

8. S. Zeković, T. Maričić, M. Vujošević: Megaprojects as an Instrument of Urban Planning and Development: Example of Belgrade Waterfront Project, in Tech4Dev 2016 UNESCO conference "From Innovation to Social Impact." Lausanne: EPFL (2016)

9. N. Vatin, D. Nemova, A. Kazimirova, K. Gureev: Increase of energy efficiency of the building of kindergarten, Advanced Materials Research, 953-954, pp. 1537-1544 (2014)

10. V. Olshevskiy: Rezultaty eksperimentalnogo opredeleniya skorostey i raskhodov v ventiliruyemykh prosloykakh NVF [The results of the experimental determination of the velocity and expenditure in ventilated interlayers of ventilated suspended facades]: Master's thesis. St.Petersburg State Polytechnical University. Saint-Petersburg, (2014)

11. D. Aristov, Yu. Glotova, Yu. Sazonova, M. Tyulenev: Fasady Rossii: sostoyanie rynka i tekhnologii [Facades of Russia: The State of the Market and Technologies]. Stroitel'stvo: nauka i obrazovanie [Construction: Science and Education], N4, paper 5. Available at http://nso-journal.ru (2015)

12. V. Chulkov, O. Kuzina, Reorganization and reconstruction of building objects, P.232-280// In .: Manufacture and use of building materials, products and systems. - Volume 1/ Under total. Ed. V.O.Chulkov (Moscow: SvRARGUS, 2009) 